\section{If not you then who?}

\author{
Steven D Williams
}

I am privileged to have recently returned from the International Society for Quality in Healthcare (ISQUa) conference, in Edinburgh, hearing the safety guru, Atul Gawande, talk about how to use checklists to improve the performance of safe and quality healthcare systems. Communication was, of course, perceived to be the essential element.

The system communicating changes about a patient's medication list is a crucial part of the Medicines Reconciliation process and the UK Professional Standards for Hospital Pharmacy Services clearly outline the professional responsibility of the pharmacy team to provide leadership and expertise to transfer information about patients' medicines at discharge to the professional(s) taking over care of the patient, including general practitioners and community pharmacists. ${ }^{1}$

In this month's issue of EJHP David Preece and coworkers present a European survey exploring pharmacists' views about communication between secondary and primary care, and the barriers to it. I for one think it makes for uncomfortable reading. If this survey is right (notwithstanding the limitation that communication

Correspondence to Mr Steven D Williams, Consultant Pharmacist in Medicine \& Medication Safety,

Department of Pharmacy, University Hospital of South Manchester, Manchester, UK;

s.williams@manchester.ac.uk may have occurred between pharmacy technicians/assistants), then surely the current system between European hospital and community pharmacists is well and truly broken? Perhaps the greatest concern is that even if the pharmacist's other main barriers to communication were fixed (by an IT system that sent the information automatically) pharmacists in the survey did not consider communicating information about medications as a core part of pharmacy practice!

So what are you going to do about it?

I am certain that you could retell a story about a patient who was readmitted to hospital either because a medication that had caused a serious adverse drug reaction had then been restarted as the community teams had not been advised the medication had been stopped; or a medication was unintentionally stopped during hospital admission causing the patient to have an adverse drug event following discharge. Is preventing such medication harms via good communication systems not a core part of pharmacy practice?

The other thing that the ISQUa conference reinforced was that with everincreasing chronic complex patients health professionals must be able to rely on IT to help improve the safety and quality of healthcare. Innovative ways to communicate about patients started on new medicines between hospital and community pharmacists already exist. In one hospital in East Lancashire, England, they have designed a system to allow hospital pharmacists and pharmacy technicians to electronically refer patients directly to their community pharmacist if (a) they are using a blister pack style 'compliance aid'; (b) they are a care home resident or (c) they would benefit from a discharge medication review within a few days of leaving hospital. (http://www.elht.nhs.uk/refer)

However, these need to become universally automatic to reach Atul Gwande's goal of the 'Future' stage of improving performance in healthcare.

Pharmacists have rightly been designated as the guardians of Medicines Reconciliation when patients are transferred between healthcare settings, but if we don't think communication about medicines on (re) admission to primary care is important then we will fail our patients...?

Competing interests None.

Provenance and peer review Commissioned; internally peer reviewed.

To cite Williams SD. Eur J Hosp Pharm 2014;21:72.

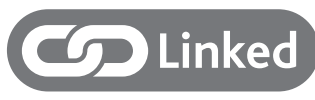

http://dx.doi.org/10.1136/ejhpharm-2013-000374

Eur J Hosp Pharm 2014;21:72.

doi:10.1136/ejhpharm-2013-000416

\section{REFERENCE}

1 Royal Pharmaceutical Society. Professional Standards For Hospital Pharmacy Services Optimising patient outcomes from medicines. London UK. July 2012. http://www.rpharms.com/unsecure-support-resources/ professional-standards-for-hospital-pharmacy.asp 